\title{
Time Series-Based School Sports System Form Reformation Research
}

\author{
Dapeng Wang ${ }^{1, *}$ and Lan Zhang ${ }^{2}$
}

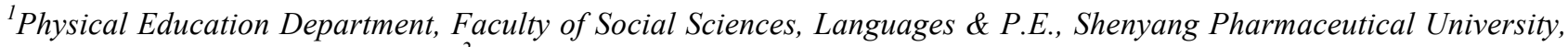
Shenyang 110016, Liaoning, China, ${ }^{2}$ Institute of Sport Science, Anshan Normal University, Anshan 114007, Liaoning, China

\begin{abstract}
With Chinese reform and opening-up, Chinese society gains stable development, with the rapid growth of economy, and Chinese sports also go through a series of reforms. The paper carries out a time series analysis of sports reformation system forming Chinese regular institutions of higher learning, it lists events changing situation in accordance with time, and constructs an analyzable time series. Then, we go ahead with effective observation and research on time series, find out its corresponding changes and development law. From system documents, educational documents to relevant colleges sports system, are all in the rising trend with time changes, and "system documents" rising trend is the largest, though relevant colleges sports system has certain rising trends, by comparison, its rising trend is the smallest. Then, we analyzed problems that colleges sports reformation process come across to make statistics, it is clear that the top three with larger influences are respectively teacher's confusion with reformation purposes, teachers feel that reformation is not good for them, and allocated sports reformation funds is deficient.
\end{abstract}

Keywords: Sports reformation, System form, Time series analysis.

\section{INTRODUCTION}

With Chinese reform and opening-up, Chinese culture, economy and politics have gone through some reforms, experiencing pains and confusion that are brought by social structural differentiation and social transformation. Chinese sports undertaking has also gone through twist and upward reformation and development path over 20 years (LIU et al., 2009). In years after reform and opening-up, Chinese society gained stable development, the economy rapidly grew, and the sports also accordingly went through a series of reforms. Specific reform measures are given in Table 1 with each period of Chinese sports reformation contents [1].

In Chinese present sports reform process, there also exist some problems such as lack of relevant theoretical knowledge, unclear sports reformation targets, short of reform power, and lack of all this hinders Chinese sports undertaking development, i.e. where the Chinese sports is going, and how to let China to be a sports power, are questions that Chinese people have always troubled with [2].

Sports development needs to use sports humanistic and social science theories as guidance. In recent years, Chinese humanistic and social science theories also set up many theories related to sports development, guiding about the sports practices through these new theories, and further enrich sports undertaking development.

\section{TIME SERIES ANALYSIS MODEL ESTABLISHMENT}

For time series analysis, the paper lists events changing the situation in accordance with time, and constructs an

*Address correspondence to this author at the Shenyang Pharmaceutical University, Shenyang 110016, Liaoning, China; Tel: +86-13591462785; E-mail: 13591462785@qq.com analyzable time series [3]. We move ahead with effective observation and research on time series, find out its corresponding changes and developmental law, and predict its future trend that corresponds to the time series analysis [4].

For time series analysis, firstly comprehend the following model (Table 2).

(1) AR(p) model:

$$
\left\{\begin{array}{l}
x_{t}=\Phi_{0}+\Phi_{1} x_{t-1}+\Phi_{2} x_{t-2}+\ldots+\Phi_{p} x_{t-p}+\varepsilon_{t} \\
\Phi_{p} \neq 0 \\
E\left(\varepsilon_{t}\right)=0, \operatorname{Var}\left(\varepsilon_{t}\right)=\sigma_{\delta}^{2}, E\left(\varepsilon_{t} \varepsilon_{s}\right)=0, s \neq t \\
E x_{s} \varepsilon_{t}=0, \forall s<t
\end{array}\right.
$$

Model with the above structure is called $\mathrm{p}$ order auto regression model, which is recorded as $\mathrm{AR}(\mathrm{p})$ here.

(2) MA(q) model:

$$
\left\{\begin{array}{l}
x_{t}=u+\varepsilon_{t}-\theta_{1} \varepsilon_{t-1}-\theta_{2} \varepsilon_{t-2}-\ldots-\theta_{q} \varepsilon_{t-q} \\
\theta_{q} \neq 0 \\
E\left(\varepsilon_{t}\right)=0, \operatorname{Var}\left(\varepsilon_{t}\right)=\sigma_{\delta}^{2}, E\left(\varepsilon_{t} \varepsilon_{s}\right)=0, s \neq t
\end{array}\right.
$$

Model with the above structure is called q order auto regression model, which is recorded as $\mathrm{MA}(\mathrm{q})$ here.

(3) $\operatorname{ARMA}(p, q)$ model:

$$
\left\{\begin{array}{l}
x_{t}=\Phi_{0}+\Phi_{1} x_{t-1}+\Phi_{2} x_{t-2}+\ldots+\Phi_{p} x_{t-p} \\
+\varepsilon_{t}-\theta_{1} \varepsilon_{t-1}-\theta_{2} \varepsilon_{t-2}-\ldots-\theta_{q} \varepsilon_{t-q} \\
\Phi_{p} \neq 0, \theta_{q} \neq 0 \\
E\left(\varepsilon_{t}\right)=0, \operatorname{Var}\left(\varepsilon_{t}\right)=\sigma_{\delta}^{2}, E\left(\varepsilon_{t} \varepsilon_{s}\right)=0, s \neq t \\
E x_{s} \varepsilon_{t}=0, \forall s<t
\end{array}\right.
$$


Table 1. Each period Chinese sports reformation contents.

\begin{tabular}{|c|c|}
\hline Time Frame & Reformation Contents \\
\hline \hline $\begin{array}{c}\text { Our socialist economic market } \\
\text { had been basically established }\end{array}$ & $\begin{array}{c}\text { Planned economic system occupied certain roles in sports system, higher planned economic system featured competi- } \\
\text { tive sports, "nationwide system" was still rewarded and respected, sports system reformation was backward relative to } \\
\text { the economic system reformation, which led to hidden troubles for future sports undertaking development. }\end{array}$ \\
\hline $\begin{array}{c}\text { During Sixteenth Congress of } \\
\text { the Chinese Communist Party }\end{array}$ & $\begin{array}{c}\text { Defined “ All-round well-off" as Chinese society development target in future years, not only sports entertainment } \\
\text { demands were closely linked to all-round well-off, but also there were great gaps between people increasing sports } \\
\text { demands and state society's sports investment. }\end{array}$ \\
\hline $\begin{array}{c}\text { Chinese economy's rapid } \\
\text { development period }\end{array}$ & $\begin{array}{c}\text { Social development built foundation for sports development, but some weak links also restricted Chinese sports devel- } \\
\text { opment, as urban and rural dual structure caused rural sports development dilemma, aging of population brought chal- } \\
\text { lenge for mass sports industry and so on. }\end{array}$ \\
\hline $\begin{array}{c}\text { Sports transformation and } \\
\text { transition period }\end{array}$ & $\begin{array}{c}\text { Competitive sports, social sports and school sports were in a "three-way" tie, they respectively formed their own sys- } \\
\text { tem, mutually separated, development was incongruous, competitive sports talents training mechanism was imperfect. }\end{array}$ \\
\hline $\begin{array}{c}\text { Sports development period } \\
\text { Sports industry was honored as "Sunrise industry", but among sections, each system liability, right and benefit were not } \\
\text { clear, lower sports socialization and marketization degrees restricted sports industry further development. }\end{array}$ \\
\hline
\end{tabular}

Table 2. Basic principles.

\begin{tabular}{|c|c|c|}
\hline$\hat{\rho}_{k}$ & $\hat{\Phi}_{k k}$ & Select Model \\
\hline \hline Tailing & P order tailing AR(p) \\
\hline q order tailing & Tailing & MA(q) \\
\hline Tailing & Tailing & ARMA(p,q) \\
\hline
\end{tabular}

Time series analysis of the model with the above structure is called $p, q$ order auto-regression model, which is recorded as ARMA(p,q).

\subsection{Stationary Sequence Modeling}

(1) Modeling steps:

During 2000 to 2010, the initial data includes our country's sports system research situation over the period of eleven years, which is listed out in the following flow: The correlation coefficient calculation sample, the model is not, And number of estimates, Model test, model optimizing, Series Forecast. Model of the process is shown in Fig. (1).

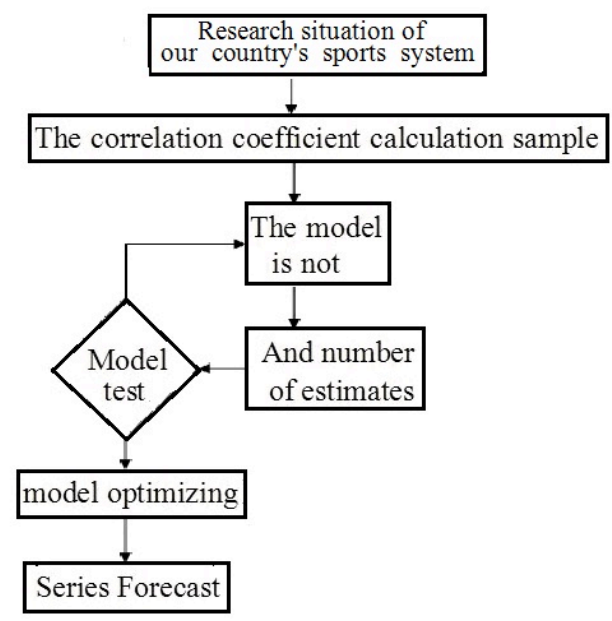

Fig. (1). Model of the process.
(2) Calculate sample correlation coefficient:

Sample autocorrelation coefficient:

$$
\hat{\rho}_{k}=\frac{\sum_{t=1}^{n-k}\left(x_{t}-\bar{x}\right)\left(x_{t+k}-\bar{x}\right)}{\sum_{t=1}^{n}\left(x_{t}-\bar{x}\right)^{2}}
$$

Partial correlation coefficient (sample):

$\hat{\Phi}_{k k}=\frac{\hat{D}_{k}}{\hat{D}}$

(3) Model recognition: tion:

(4) Sample correlation coefficient approximate distribu-

Bartlett: $\hat{\rho}_{k} \sim N\left(0, \frac{1}{n}\right), n \rightarrow \infty$

Quintuple: $\hat{\Phi}_{k k} \sim N\left(0, \frac{1}{n}\right), n \rightarrow \infty$

(5) Parameter estimation:

Parameters to be estimated have $p+q+2$ unknown parameters pieces. Commonly used estimation methods are: moment estimation, and maximum likelihood estimation.

(6) Model significance test:

Purpose: test model's validness (whether sufficiently extract information or not) [5] 


\section{Test objects: Residual sequence}

Evaluation principle: A good fitting model should be able to extract the observed value for correlation information of sequence samples that the residual sequence should be the data that needs to be discussed. On the contrary, it needs to be distinguished according to cases.

Null hypothesis: Chinese sports system research situation initial data.

$$
H_{0}: \rho_{1}=\rho_{2}=\ldots=\rho_{m}=0, \forall m \geq 1
$$

Alternative hypothesis: Corresponding residual sequence is the data that needs to be discussed:

$$
H_{1} \text { At } \text { least it has one } \rho_{k} \neq 0, \forall m \geq 1, k \leq m
$$

Test statistics:

LB statistics: $L B=n(n+2) \sum_{k=1}^{m}\left(\frac{\hat{\rho}_{k}^{2}}{n-k}\right) \sim \chi^{2}(m)$

Parameters significance testing:

Purpose: Test every unknown corresponding parameter whether its value is zero or not. Delete these insignificant parameters.

$$
H_{0}: \beta_{j}=0 \quad H_{1}: \beta_{j} \neq 0
$$

Test statistics:

$$
T=\sqrt{n-m} \frac{\hat{\beta}_{j}-\beta_{j}}{\sqrt{a_{j j} Q(\widetilde{\beta})}} \sim t(n-m)
$$

Model optimization:

Problem posing: Here, we assume that the model qualifies corresponding tests, which shows that the data is in certain feasible intervals, and thus the model can effectively get favorable results.

Optimization purpose: Select relative optimal model

Sequence forecasting:

Linear prediction function

$$
x_{t}=\sum_{i=0}^{\infty} C_{i} x_{t-1-i}
$$

Minimum forecasting variance principle

$$
\operatorname{Var}_{\hat{x}_{t(l)}}\left[e_{t}(l)\right]=\min \left\{\operatorname{Var}\left[e_{t}(l)\right]\right\}
$$

Take it as a factor in the next model analysis.

\subsection{Non-Stationary Sequence Modeling}

Firstly, stationary operation on data is required, and furthermore, we established ARIMA (p, q) model to solve the process, which structure has been introduced in the following the equation:

Model structure:

$$
\left\{\begin{array}{l}
\Phi(B) \nabla^{d} x_{t}=\Theta(B) \varepsilon_{t} \\
E\left(\varepsilon_{t}\right)=0, \operatorname{Var}\left(\varepsilon_{t}\right)=\sigma_{\varepsilon}^{2}, E\left(\varepsilon_{t} \varepsilon_{s}\right)=0, s \neq t \\
E x_{s} \varepsilon_{t}=0, \forall s<t
\end{array}\right.
$$

Modeling steps: Non-stationary sequence modeling flowchart has the following steps: The observed sequence value obtained, Stationary test, Difference operation, Variables test, Fitting ARMA model, Analysis result, as shown in Fig. (2).

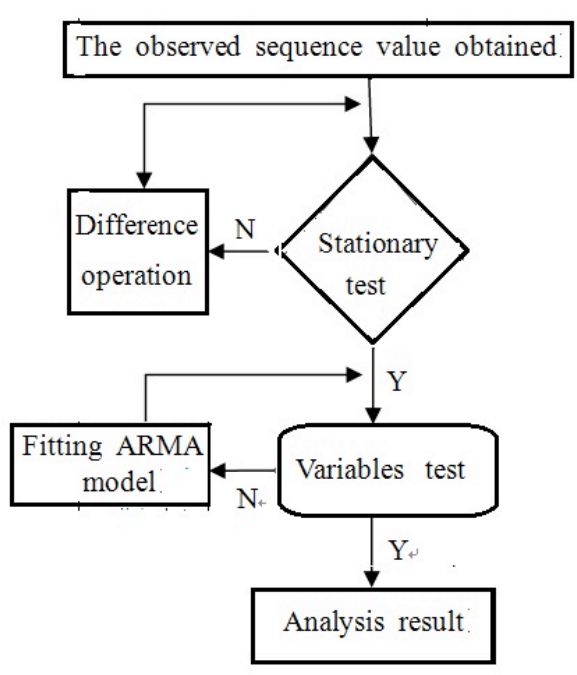

Fig. (2). Non-stationary sequence modeling flowchart.

\section{MOLD APPLICATION AND CORRESPONDING DATA HANDLING}

\subsection{Colleges Sports System Research Situation}

For colleges sports reform's system is formed, which in the first place, mainly discusses the colleges sports system research situation. Here, the eleven years sports system related articles from the year 2000 to 2010 were selected to collect statistics and make a summary. The result of this summary is given in Table $\mathbf{3}$.

Corresponding to the above data, a development trend is shown in Fig. (3). Figure 3 clearly shows that the system documents, education documents, and relevant college sports system, all show a rising trend with time change, among them the system documents rising trend is the largest, whereas the colleges sports system has the smallest rising trend.

\subsection{College's Sports System Changes Since the Founding of New China}

Since the new China was founded in 1949, Chinese colleges' sports system changes could roughly be divided into five stages, which show different features, and keeping those features, we created a list analyzing changes of relative Chinese colleges' sports system as shown in Table 4.

In analyzing Chinese colleges relevant sports system changes, it is clear that though Chinese colleges sports situation shows a positive development, its reform process also came across some problems. A statistics of these problems is presented in Table $\mathbf{5}$.

Corresponding to the above data, a "two-axis bar graph" is drawn in Fig. (4). 
Table 3. Colleges sports system research situation.

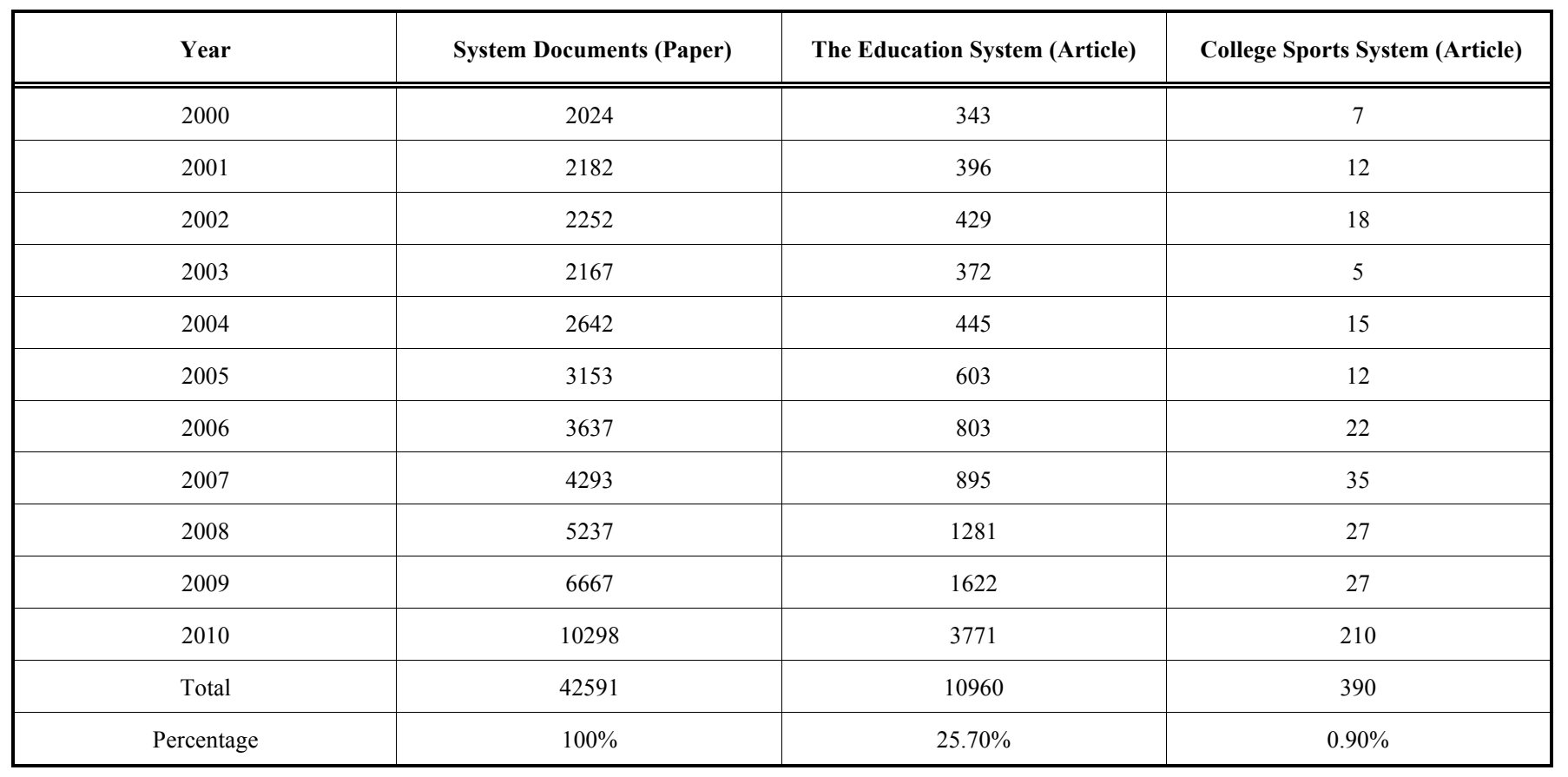

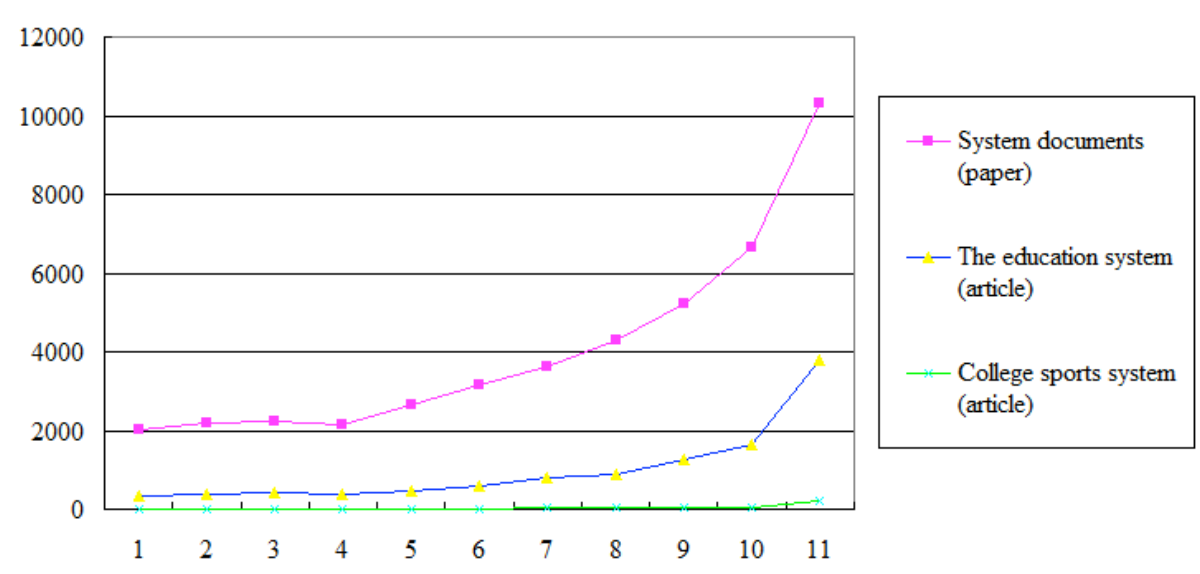

Fig. (3). Sports system of colleges and colleges.

Table 4. Chinese colleges sports system changes.

\begin{tabular}{|c|c|}
\hline Time Frame & Features \\
\hline $\begin{array}{l}\text { College sports system blueprint stage } \\
\text { (Year 1949-1956) }\end{array}$ & $\begin{array}{l}\text { It mainly imitated the Soviets college sports system, from which it took the imitation of the Soviets } \\
\text { sports system of "Prepare for safeguarding nation and labor" as base, using "three basic" as teaching } \\
\text { guiding thought. }\end{array}$ \\
\hline $\begin{array}{l}\text { College sports system creation stage } \\
\text { (Year 1957-1965) }\end{array}$ & $\begin{array}{l}\text { It formulated surrounding features as strengthening physique and consolidating national defense, } \\
\text { gradually formed the frame of system. }\end{array}$ \\
\hline $\begin{array}{l}\text { College sports system disorder development stage } \\
\text { (Year 1966-1976) }\end{array}$ & $\begin{array}{l}\text { During "the Great Cultural Revolution", due to unstable politics situation influences at that time, } \\
\text { Chinese colleges' sports system suffered heavy damages and showed disorder development features. }\end{array}$ \\
\hline $\begin{array}{l}\text { College sports system recovery stage } \\
\text { (Year 1977-1992) }\end{array}$ & $\begin{array}{l}\text { In this stage, with the purpose of training students to develop habit of physical exercises, it mainly } \\
\text { faced all students, enhanced students' physique, and thus it penetrated "Health Comes First" educa- } \\
\text { tional concept. }\end{array}$ \\
\hline $\begin{array}{l}\text { College sports rapid development stage } \\
\qquad(1993 \text {-now) }\end{array}$ & $\begin{array}{l}\text { Followed by constantly deepen of "Health Comes First" and "Advanced sports school courses and } \\
\text { other aspect reforms", Chinese colleges sports system has gradually tended to normalization and } \\
\text { scientization. }\end{array}$ \\
\hline
\end{tabular}


Table 5. Sports reform process problems statistics.

\begin{tabular}{|c|c|c|c|}
\hline 1 & Teachers' confusion with reform purposes & 198 & $74.40 \%$ \\
\hline 3 & Allocated sports reform funds is deficient & 162 & $61.10 \%$ \\
\hline 4 & Teachers lack of relevant accurate information regarding reforms & 147 & $55.50 \%$ \\
\hline 6 & School facilities, equipment are in short supply & 129 & $48.70 \%$ \\
\hline 7 & Short of qualified staff & 118 & $44.50 \%$ \\
\hline 8 & Teachers are not willing to reform or listen to new concepts & 97 & $36.60 \%$ \\
\hline 12 & Collapsed planning and implementation & 61 & $23 \%$ \\
\hline 13 & Lack of contacting with outer resources groups & 49 & $18.50 \%$ \\
\hline 14 & Lack of coordinated activities to let new concepts to be accepted & 38 & $14.30 \%$ \\
\hline 15 & Relative proper person came across setbacks and difficulties during reformation trial & 30 & $11.30 \%$ \\
\hline 16 & Lack of contacting with schools that considered to do similar reforms & 28 & $10.60 \%$ \\
\hline- & Total selected times & 1604 & - \\
\hline
\end{tabular}

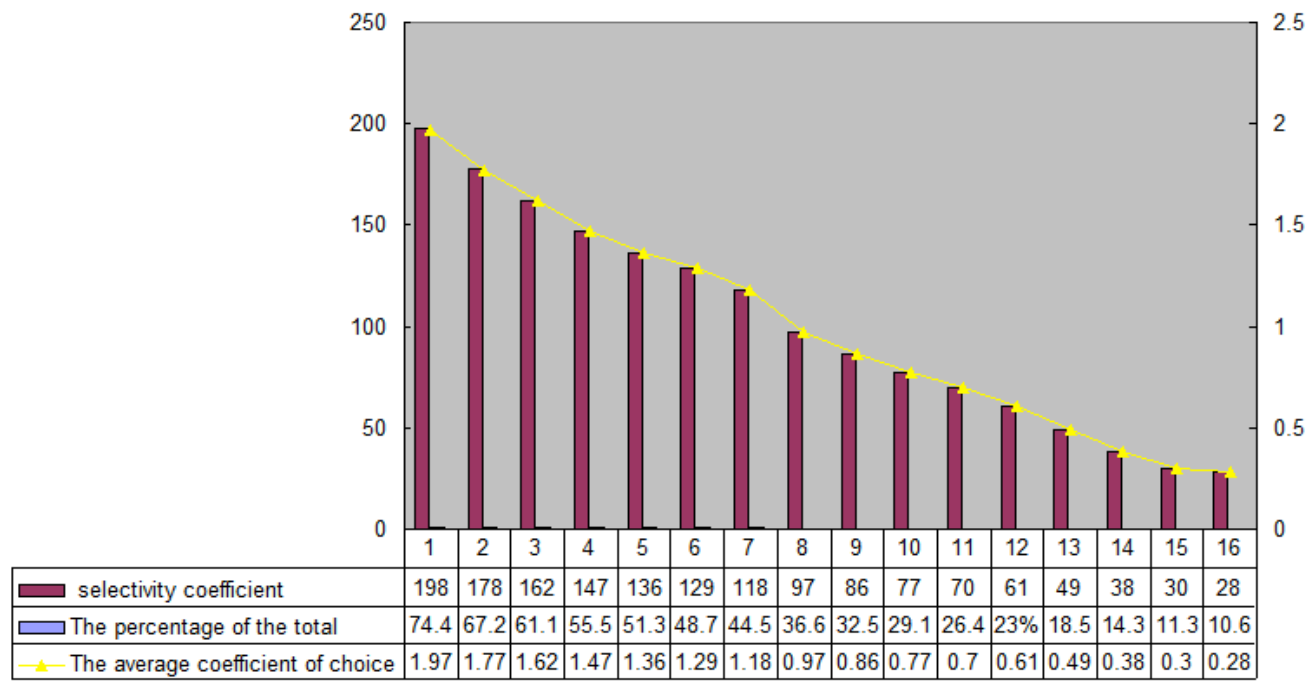

Fig. (4). The statistical problems in the process of sports reform.

From the above analysis and statistics of problems that college sports reform process underwent, it is clear that top three influence factors are teacher's confusion with reformation purposes, teachers feel that reformation is not good for them, and that the allocated sports reformation funds is deficient.

\section{CONCLUSION}

With Chinese reform and opening-up, Chinese culture, economy and politics have gone through some reforms, ex- periencing pains and confusion that are brought by social structural differentiation and social transformation, Chinese sports undertaking has also gone through twist and upward reformation and development path over 20 years. In years after reform and opening-up, Chinese society gains stable development, Chinese economy rapidly grows, and Chinese sports also accordingly go through a series of reforms. Sports development needs to use sports humanistic and social science theories as guidance. In recent years, Chinese humanistic and social science theories also set up many theories 
related to sports development, guiding sports practices in these new theories, and further enrich sports undertaking development. System documents, educational documents and relevant colleges sports system, all are in the rising trend with time changes. And system documents rising trend is the largest, whereas colleges sports system rising trend is the smallest.

\section{CONFLICT OF INTEREST}

The authors confirm that this article content has no conflict of interest.

\section{ACKNOWLEDGEMENTS}

Declared none.

\section{REFERENCES}

[1] C. Nan-Yue, "Harmonious society calls for society harmonious GDP," J. Yunnan Fina. Trade Inst., vol. 21, no. 6, pp. 81-85, 2005.

[2] F. Liwei, and L. Jiyao, "The development of the economy and society calls to create the new mode of economic development-"green and harmonious" development," Val. Eng., vol. 25, no. 5, pp. 29-31, 2006.

[3] L. Chang-ming, and G. Bin, "Power of harmony-against the background of chinese culture," J. Tianjin Coll. (Soc. Sci.)., vol. 11 , no. 5, pp. 453-457, 2009.

[4] W. Xiaoguang, "Thoughts and analyses of the construction of harmonious enterprises in China," Res. Dev., no. 5, pp. 57-60, 2007.

[5] X. Xiao-yue, "Reflections on the modern value of the ideas of lao zi," J. Anhui Coll. (Philos. Soc. Sci.)., vol. 30, no. 6, pp. 6-8, 2006.

Received: June 10, 2015

Revised: July 29, 2015

Accepted: August 15,2015

(C) Wang and Zhang; Licensee Bentham Open.

This is an open access article licensed under the terms of the (https://creativecommons.org/licenses/by/4.0/legalcode), which permits unrestricted, noncommercial use, distribution and reproduction in any medium, provided the work is properly cited. 